\title{
The other China
}

Dr Yuan Lee is the Nobel prizewinning chemist from Berkeley, California, who has returned to the 'other' China, the one whose capital is Taipei, to be president of the Academy of Sciences there. He described it, last week, as a challenging task, implying that there is much to do before it becomes a centre of excellence.

Unlike most other organizations with this title, the academy is more a research institute in its own right than a sponsor of research institutes elsewhere. Lee says there are 1,500 academics on the staff, spending a total of US $\$ 150$ million a year and covering the humanities as well as science.

Assessment and evaluation is Lee's starting point, which he says has already uncovered the truth that the Chinese language department at Taipei has outstanding expertise and is likely to be further strengthened. He also plans to pay personal atten- tion to the development of chemistry at Taipei, believing there is great potential in the field.

Last week, he spoke with feeling of the need for sympathetic management of young people at research institutions. "We are not very good at telling young people that they are good at what they do". Tolerance among colleagues is critical in the pursuit of excellence. In making appointments, institutions should consider "what will be good for the institution in five or six years time".

As conference organizers will readily appreciate, there are diplomatic problems to be solved when people from the two Chinas appear on the same programme. Last week, these were mostly solved because of the circumstance that Drs Lu (from Beijing) and Lee (from Taipei) became personally wellacquainted with each other when they were both living in the United States. entranced his audience with colour slides (the leaning tower seen through a window in one of them) of the battered mediaeval buildings in which his unique institution is housed. It is a frankly élitist place, boasting of Volterra, Levi-Civita and Enrico Fermi among its alumnae, which was converted in Napoleonic times into one of the then-four grandes écoles of the Empire.

There is no single recipe for the education of an élite, Picasso modestly proclaimed, offering Pisa simply as one way of doing the job. His telling point was that Pisa's Normale is not a comprehensive university, but one skewed towards mathematics, physics, geography and the history of art by tradition and the scholarly interests of its present staff. In particular, 50,000 or so students are not a necessary condition of a university.

Something like that seems to be the ambition elsewhere, but especially on the mainland of Asia, where the numbers are unavoidably big and where people are busily creating universities overnight. In South Korea, according to KunMo Chung, president of the Institute of Advanced Engineering at Seoul, the whole university system has been reconstructed in the past three and a half decades, since the ending of the Korean War. An essential part of the recipe for the clutch of universities in Korea that have excelled is the recruitment of expatriate Koreans who have been educated elsewhere; Chung's own engineering $\mathrm{PhD}$ is from the University of Michigan.

Chung's message last week was of the globalization of the university, not merely because people are now mobile, but because of the Internet and the communications technology that has made that possible. Sooyung Chang, president of the
Pohang University of Science and Technology, explained that there are already 167 universities, but that South Korea still depends on the rest of the world (the United States, Britain and, in the future, Australia) for much of its graduate education. Engineering is the favourite area of study, and industry is a generous source of support for a few select institutions, such as Chang's, which is supported by a steel company, and Chung's, which is supported by the Daewoo group. But most South Korean universities are very poorly supported by the government.

Among many other things, KunMo Chung masterminds South Korea's programme to improve the status of the existing universities by means of a competitive programme for the creation of what are called - what else? - centres of excellence. "If you have centres of excellence already it's easy", he said last week. But in South Korea most research used to be second-rate.

The idea now is that groups of individuals (they must be drawn from at least five institutions) apply for a standard grant of US\$1 million a year for 9 years; a precondition for those in engineering is that they must have the promise of at least 5 times as much from industrial partners. The projects are mostly technically orientated (the industrial partners are looking for a return) and are externally reviewed every three years. Chung said last week that 35 of these centres have been created in just two years. One consequence, he said, is that South Korean academics have a new confidence.

The pattern of generous support for research in science and engineering within technically skewed institutions seems to be the general pattern in eastern Asia.
The flashiest development of all seems to be that of the Hong Kong University of Science and Technology (HKUST), a brand-new campus founded in 1988 on a finger of one of Hong Kong's islands dipping steeply into the sea, and now covered with some of post-modernism's most spectacular buildings at the other end of the architectural spectrum from those at Pisa.

Dr Chia-Wei Woo, the first (and present) vice-chancellor, is a man in a hurry. Last week, he explained that when he had taken the new job, he and his wife stayed up late every night building a network among other ethnic Chinese academics around the world, seeking to identify potential teachers. There are now $400(90$ per cent of them from the United States), but the number is growing at 10 a month.

HKUST is and plans to remain a single-minded institution. From the outset, it has had separately registered commercial companies to take charge of its industrial liaison, in which Hong Kong's industry is said to be an enthusiastic partner driven by the recognition that Hong Kong is in "economic transition from low to hightechnology industry".

Woo reckons that each staff member already brings in $\$ 50,000$ a year by way of grants and contracts, for projects such as the transmission of television signals by telephone line and the provision of windwarning systems for Hong Kong's airports. At the end of its first four-year teaching cycle earlier this year, the university awarded 576 first degrees, 212 masters' degrees and one $\mathrm{PhD}$ (a transfer from elsewhere). HKUST aims at 7,000 students within eight years, or to operate on the scale and in the style of Massachusetts Institute of Technology. Woo boasts that one member of staff has already been poached by another university.

China proper, inevitably, is a still bigger task. Yongxiang Lu, a vice-president of the Chinese Academy of Science, pointed out last week that China already has 1,075 universities and colleges (perhaps a third as many as the tertiary institutions in the United States), but that a third of the students study engineering, compared with a fifth in Japan and a twentieth in the United States.

But even the 1.29 million engineering students in China cannot meet the demands of the "socialist market economic system", so that growth is the order of the day. How to arrange for that while keeping the economy ticking over? Lu guesses that half of his own university's budget comes from industry. Universities willingly accept part-time appointments and encourage academics to set up technical companies (one of which has designed China's most powerful computer now being marketed by a Hong Kong company), and will take on development as well as research contracts.

In short, the new universities of east 